\title{
Concrete Filled Square Steel Tubular Deep Beam subjected to Bending-shear
}

\author{
Kojiro Uenaka ${ }^{1,{ }^{*}}$ and Hisao Tsunokake ${ }^{2}$ \\ ${ }^{1}$ Kobe City College of Technology, Department of Civil Engineering, 6512194 Kobe, Japan \\ ${ }^{2}$ Osaka City University, Department of Urban Engineering, 5588585 Osaka, Japan
}

\begin{abstract}
This study aims to investigate experimentally mechanical characteristics of S-CFT deep beam under bending-shear through symmetrically three-point loading test method with a constant axial load. Selected test parameters are shear span and the width-to-thickness ratios, which are ranging from 1.0 to 1.5 and 62.5 to 200 , respectively. As the results, observed failure modes of the specimens with width-to-thickness ratio being 200 were local buckling of steel tube associated with shear failure of in-filled concrete between two supports. No effect of the constant axial load on bending-shear capacities can be found. The experimental strength of the specimens with shear span ratio between 1.0 and 1.5 can be predicted by the accumulative strength being composed of RC deep beam and web steel plate.
\end{abstract}

\section{Introduction}

Concrete filled steel tubular, CFT[1], member consists of hollow circular/square steel tube and filled concrete, as shown in Fig. 1. The CFT member holds good deformability owing to confined strength between the steel tube and filled concrete.

Reviewing the past studies on concrete filled square steel tubular, S-CFT, member, we can first find investigations of S-CFT member under bending-shear and axial load[2-3]. Next, Sakino et al.[4] carried out S-CFT stub column test under cyclic shear force test[4]. Nakahara[5] conducted flexural behavior of S-CFT beam column under two parameters, namely single and double curvature. However, width-to-thickness ratios being less than 50 of square steel tube of S-CFT is mainly discussed in the previously research. The detailed mechanical behavior of S-CFT member with the smaller width-to-thickness ratio is given in Ref. [1].

This study aims to investigate bending-shear characteristics of deep squared CFT(SCFT) beam, the width-to-thickness ratios of which are 62.5 and 200, through symmetric three-point loading test methods with a constant axial load. The selected testing parameters are the shear-span ratio, width-to-thickness ratio and axial strength. Method to predict bending shear capacity with the large width-to-thickness ratio is given.

\footnotetext{
*Corresponding author: uenaka@kobe-kosen.ac.jp
} 


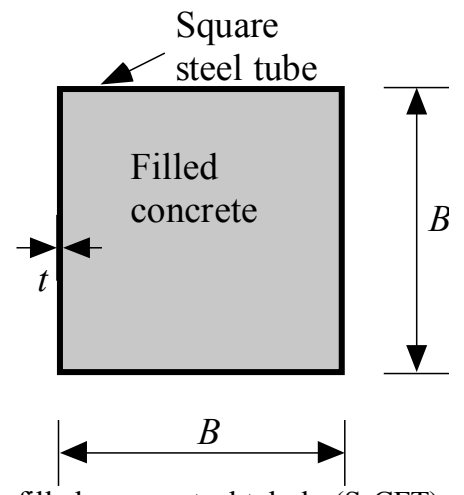

Figure 1. Cross section of concrete filled square steel tubular(S-CFT).

Table 1. List of the specimens.

\begin{tabular}{|c|c|c|c|c|c|c|c|c|c|c|}
\hline \multirow[b]{2}{*}{ No. } & \multirow[b]{2}{*}{ Tag } & \multicolumn{8}{|c|}{ Square steel tube } & \multirow[b]{2}{*}{$\begin{array}{c}\text { Con- } \\
\text { crete } \\
f_{c}^{\prime} \\
(\mathrm{MPa})\end{array}$} \\
\hline & & $\begin{array}{l}\text { Thick. } \\
t(\mathrm{~mm})\end{array}$ & $\begin{array}{l}\text { Width } \\
B(\mathrm{~mm})\end{array}$ & $\begin{array}{c}\text { Span } \\
\text { length } \\
L(\mathrm{~mm})\end{array}$ & $\begin{array}{l}\text { Width-to- } \\
\text { thickness } \\
\text { ratio } \\
B / t\end{array}$ & $\begin{array}{c}\text { shear- } \\
\text { span } \\
\text { ratio } \\
a / B\end{array}$ & $\begin{array}{c}\text { Yielding } \\
\text { point } \\
f_{y}(\mathrm{MPa})\end{array}$ & $\begin{array}{c}\text { Fracture } \\
\text { point } \\
f_{u}(\mathrm{MPa})\end{array}$ & $\begin{array}{c}N / \\
N_{c u}\end{array}$ & \\
\hline 1 & t32-s15-n02 & 3.2 & \multirow{8}{*}{200} & 600 & 62.5 & 1.5 & 353.0 & 428.4 & 0.2 & 27.5 \\
\hline 2 & t32-s15-n01 & 3.2 & & 600 & 62.5 & 1.5 & 353.0 & 428.4 & 0.1 & 27.5 \\
\hline 3 & t32-s10-n02 & 3.2 & & 400 & 62.5 & 1.0 & 353.0 & 428.4 & 0.2 & 27.5 \\
\hline 4 & t32-s10-n01 & 3.2 & & 400 & 62.5 & 1.0 & 353.0 & 428.4 & 0.1 & 27.5 \\
\hline 5 & t10-s15-n02 & 1.0 & & 600 & 200.0 & 1.5 & 216.5 & 320.0 & 0.2 & 27.5 \\
\hline 6 & t10-s15-n01 & 1.0 & & 600 & 200.0 & 1.5 & 216.5 & 320.0 & 0.1 & 27.5 \\
\hline 7 & t10-s10-n02 & 1.0 & & 400 & 200.0 & 1.0 & 216.5 & 320.0 & 0.2 & 27.5 \\
\hline 8 & t10-s10-n01 & 1.0 & & 400 & 200.0 & 1.0 & 216.5 & 320.0 & 0.1 & 27.5 \\
\hline
\end{tabular}

Note : $a=$ shear span length $(=L / 2), N=$ axial load, $N_{c u}=$ ultimate axial force

\section{Test method}

\subsection{Test specimens}

Table 1 summarizes the detail of the test specimens. The specimens have commonly square steel tube's width $B=200 \mathrm{~mm}$. Thicknesses of the steel tubes $(t)$ are 1.0 and $3.2 \mathrm{~mm}$. Therefore, width-to-thickness $\operatorname{ratios}(B / t)$ are 62.5 and 200, respectively. Two shear span lengths $(L=2 a)$ are 400 and $600 \mathrm{~mm}$, thus, shear span $\operatorname{ratios}(a / B)$ are 1.0 and 1.5 .

Axial strength ratio of the S-CFT deep beam is described in Table 1, the $N_{c u}$ in which is calculated from below.

$$
N_{c u}=f_{c}^{\prime} A_{c}
$$




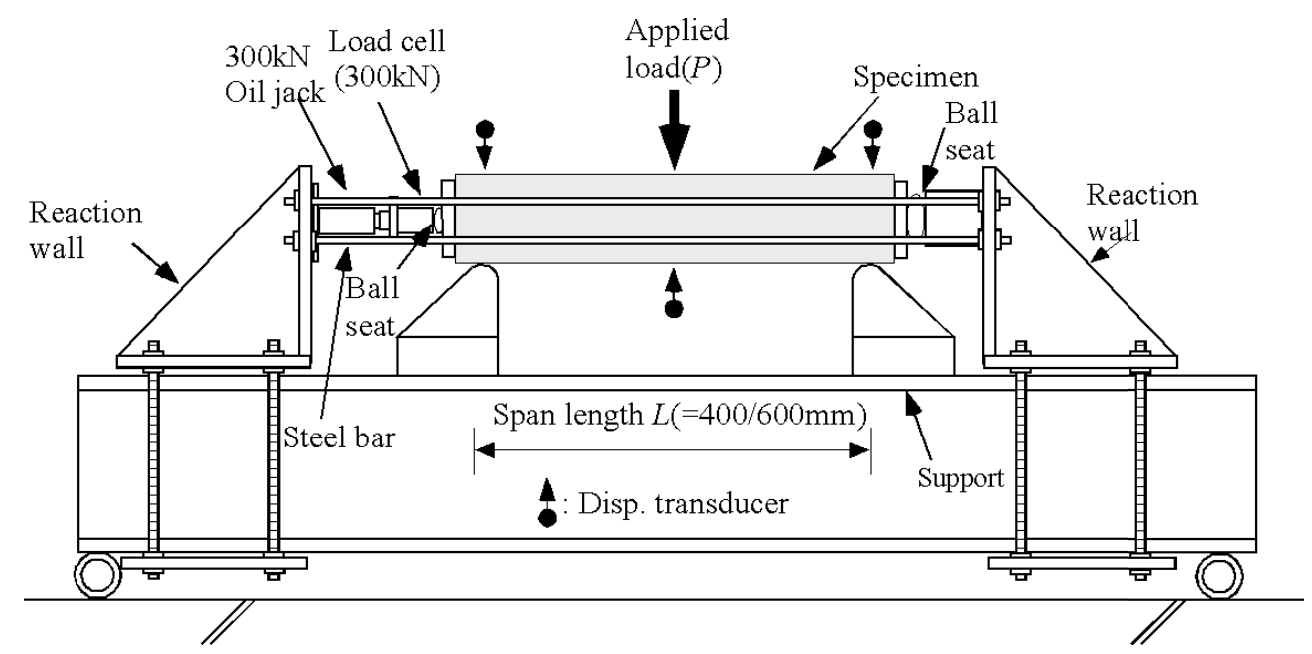

Figure 2. Test apparatus.

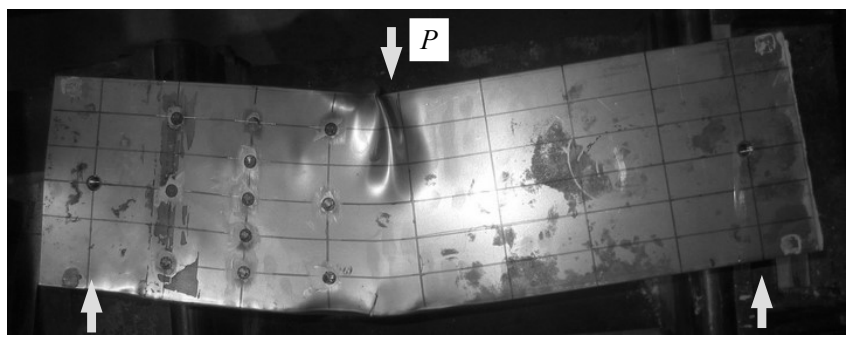

a)Square steel tube

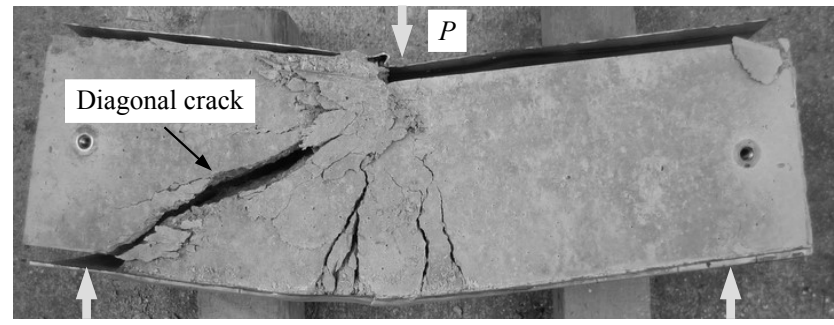

b)In-filled concrete

Figure 3. Failure mode(t10-s15-n02).

where $f_{c}$ ' and $A_{c}$ are concrete strength and its cross-sectional area.

Figure 2 shows loading method of this investigation. The symmetric three-point loading test method was employed. The constant axial load can be introduced to the specimen by the PC steel bar and two reaction walls.

\subsection{Measurements}




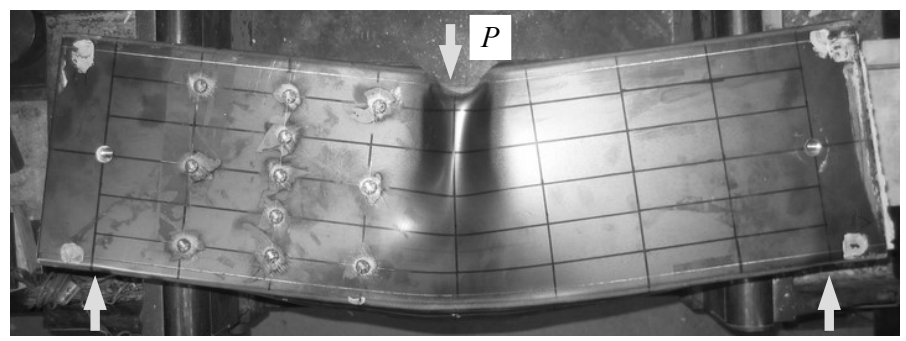

a)Square steel tube

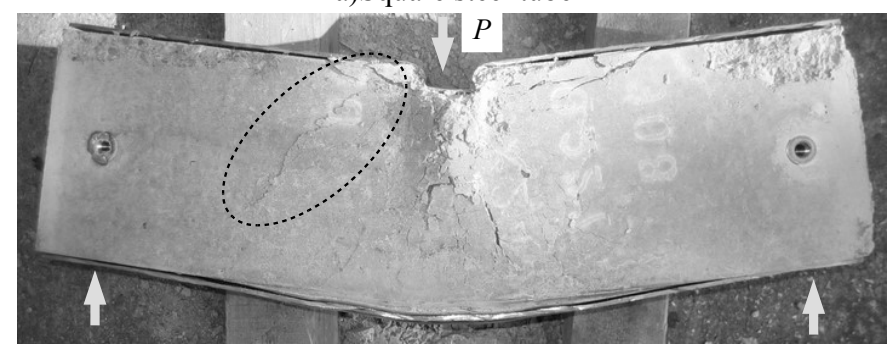

b)In-filled concrete

Figure 4. Failure mode(t32-s15-n01).

Three displacement transducers were arranged under the mid-span of the specimen and upper of the two supports under the constant axial load $(N)$, as shown in Fig. 2. The monotonic bending-shear action was applied to the specimens until fatal failure.

\section{Results and discussion}

\subsection{Failure modes}

Figure 3a) and b) show the detailed failure of the specimen with $B / t$ being 200 . The local buckling of square steel tube and tensile cracking of steel tube occurred. The large diagonal crack of in-filled concrete can be found clearly.

Figures 4a) and b) show the failure mode of the specimen t32-s15-n01. Local buckling of steel tubes and bending cracking of steel tube can be observed. In addition, compressive failure of in-filled concrete at the loading point occurred as shown in Fig. 4b). Whereas, no large diagonal crack of in-filled concrete appeared in the specimen with $B / t$ being 62.5 .

\subsection{Load-displacement}

Figures 5a), b) provide the relationship between applied load $(P)$ and the angle of rotation of the deep beam $(\theta)$, namely, central displacement $(\delta)$ divided into shear span length $a$ $(=L / 2)$. From the figures, it can be observed that applied loads $(P)$ kept maximum the angle $\theta=0.04$. It should be noted that no effect of axial strength on deformability of S-CFT deep beam can be found. 


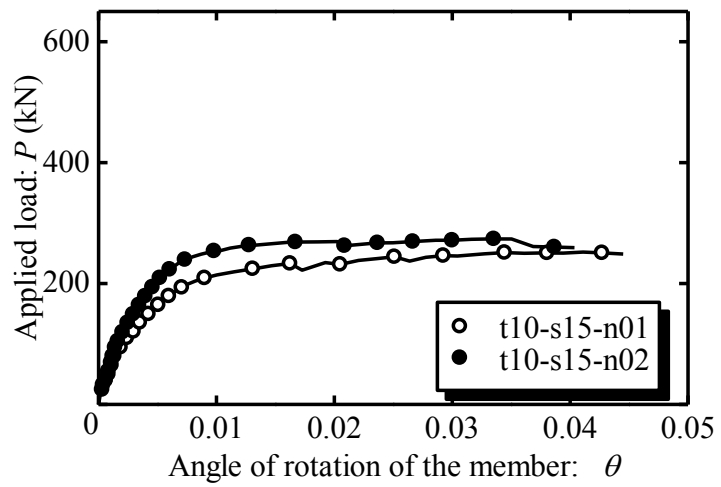

a) $t=1.0 \mathrm{~mm}$

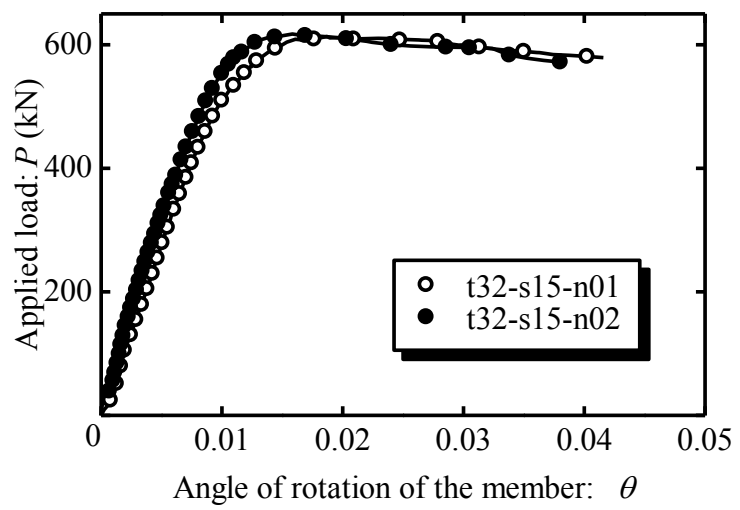

b) $t=3.2 \mathrm{~mm}$

Figure 5. Applied load and angle of rotation.

\subsection{Shear strength}

\subsubsection{Predicted method}

According to JSCE[6], shear strength of RC beam can be expressed as below,

$$
V_{c d d}=\beta_{d} \cdot \beta_{n} \cdot \beta_{p} \cdot \beta_{a} \cdot f_{d d} \cdot D_{c} \cdot d
$$

where,

$$
\begin{aligned}
& f_{d d}=0.19 \sqrt{f_{c d}{ }^{\prime}}, \beta_{d}=\sqrt[4]{1000 / d} \quad, \quad \beta_{n}=1+2 M_{0} / M_{u d} \quad, \quad \beta_{p}=\frac{1+\sqrt{100 p_{v}}}{2}, \\
& \beta_{a}=\frac{5}{1+(a / d)^{2}} \text { and } p_{v}=\frac{t}{d}
\end{aligned}
$$

where $f_{c d}$ ': concrete strength $\left(f_{c d}{ }^{\prime}=f_{c}{ }^{\prime}\right), d$ : effective $\operatorname{depth}(B-t / 2, \mathrm{~mm}), D_{c}$ : depth of in-filled concrete $(B-2 t), M_{u d}$ : pure bending strength and $M_{o}$ : bending moment obtained from below. 
Table 2. Experiment and estimation.

\begin{tabular}{ccccc}
\hline \multirow{2}{*}{ No. } & \multirow{2}{*}{ Tag } & $\begin{array}{c}V_{\text {exp }} \\
(\mathrm{kN})\end{array}$ & $\begin{array}{c}V_{\text {est }} \\
(\mathrm{kN})\end{array}$ & \begin{tabular}{c}
$V_{\text {exp }}$ \\
\cline { 3 - 5 }
\end{tabular} \\
\hline 1 & $\mathrm{t32-s15-n02}$ & 309 & 313 & 0.99 \\
\hline 2 & $\mathrm{t} 32-\mathrm{s} 15-\mathrm{n} 01$ & 307 & 309 & 0.99 \\
\hline 3 & $\mathrm{t} 32-\mathrm{s} 10-\mathrm{n} 02$ & 365 & 388 & 0.94 \\
\hline 4 & $\mathrm{t} 32-\mathrm{s} 10-\mathrm{n} 01$ & 347 & 377 & 0.92 \\
\hline 5 & $\mathrm{t} 10-\mathrm{s} 15-\mathrm{n} 02$ & 137 & 141 & 0.97 \\
\hline 6 & $\mathrm{t} 10-\mathrm{s} 15-\mathrm{n} 01$ & 126 & 124 & 1.02 \\
\hline 7 & $\mathrm{t} 10-\mathrm{s} 10-\mathrm{n} 02$ & 184 & 211 & 0.87 \\
\hline 8 & $\mathrm{t} 10-\mathrm{s} 10-\mathrm{n} 01$ & 197 & 184 & 1.07 \\
\hline
\end{tabular}

$$
M_{o}=\frac{N}{6} B
$$

Next, buckling strength of steel tubes proposed by JSSC[7] is expressed as below,

$$
V_{s u}=\tau_{c u l} \cdot A_{w}
$$

where $A_{w}$ : cross-sectional area of web and $\tau_{c u l}$ can be expressed as below,

$$
\begin{aligned}
\tau_{c u l} & =\frac{f_{y}}{\sqrt{3}}\left(R_{r}<0.60\right) \\
\tau_{c u l} & =\left(\frac{0.6}{R_{r}}\right)^{0.32} \phi_{p} \cdot \frac{f_{y}}{\sqrt{3}} \quad\left(0.60<R_{r}\right)
\end{aligned}
$$

where $\phi_{p}$ is the resistant factor. The parameter of width-to-thickness ratio $\left(R_{r}\right)$ of square steel tube can be calculated from below,

$$
R_{r}=\frac{1}{\pi} \sqrt{\frac{12\left(1-v^{2}\right)}{k}} \cdot \sqrt{\frac{f_{y}}{3 E_{s}}} \cdot \frac{D}{t_{w}}
$$

where $E_{s}$ and $v$ are Young's modulus and Poisson's ratio of the square steel tube. The buckling factor $k$ can be obtained from below.

$$
\begin{aligned}
& k=5.34+4.00(D / a)^{2} \quad(a / D>1) \\
& k=4.00+5.34(D / a)^{2} \quad(a / D \leq 1)
\end{aligned}
$$




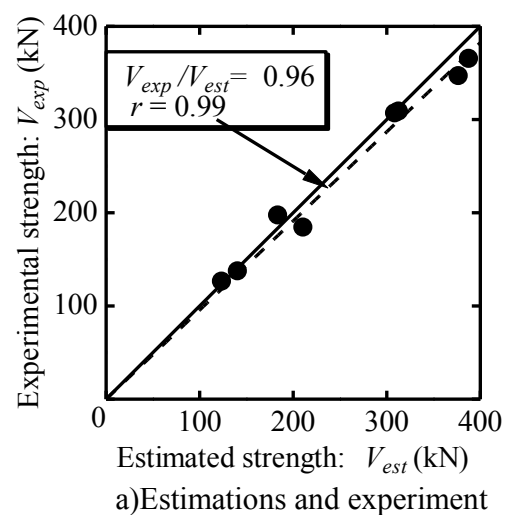

Figure 6. Shear strength.

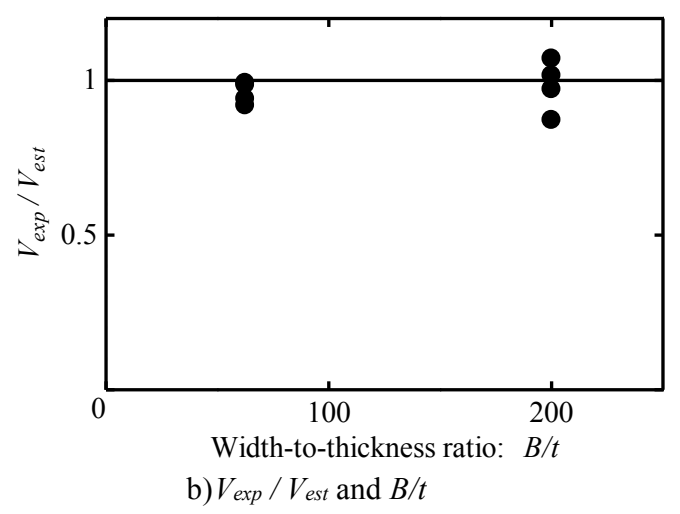

Last, the predicted shear strength $V_{\text {est }}$ is sum of shear strength of deep RC beam $\left(V_{c d d}\right)$ and buckling strength of $V_{s u}$, namely,

$$
V_{e s t}=V_{c d d}+V_{s u}
$$

Table 2 compares the experimental and calculated strengths, $V_{\text {exp }}$ and $V_{\text {est }}$, respectively.

\subsubsection{Comparison of experimental shear strength}

Figure 6a) shows the relationship between experimental shear strength $V_{\exp }$ and estimated strength $V_{\text {est }}$ calculated by Eq. (8). From the figure, The experimental strength $V_{\text {exp }}$ is in good agreement with estimated strength $V_{\text {est }}$, namely, with the ratio $V_{\text {exp }} / V_{\text {est }}=0.96$ and good correlation factor $r=0.99$.

The strength ratio $\left(V_{\text {exp }} / V_{\text {est }}\right)$ is plotted against width-to-thickness ratio $B / t$ as shown in Fig. 6b). No effect of the ratio $B / t$ on strength ratio $V_{\text {exp }} / V_{\text {est }}$ can be found.

\section{Concluding remarks}

Eight specimens of concrete filled square steel tubular(S-CFT) deep beam subjected to bending-shear under constant axial load were examined. From the results, following remarks can be drawn.

1. Observed failure modes are local buckling of square steel tube with/without shear failure of filled concrete.

2. No effect of the constant axial load ratio on bending-shear deformability on S-CFT deep beam can be found.

3. The ultimate bending-shear capacity of S-CFT deep beam can be correctly predicted by sum of the same method of RC deep beam and steel buckling strength.

\section{References}


1. Architectural Institution of Japan: Recommendations for Design and Construction of Concrete Filled Steel Structures, Maruzen(2008)(in Japanese)

2. M. Tomii, K. Sakino, Transactions of the Architectural Institute of Japan, 275, 5565(1979)

3. M. Tomii, K. Sakino, Transactions of the Architectural Institute of Japan, 280, 111120(1979)

4. K. Sakino, H. Ishibashi, Transactions of the Architectural Institute of Japan, 353, pp. 81-91(1985)

5. H. Nakahara, K. Sakino, Proc. of the 12th World Conference on Earthquake Engineering, 1923(2000).

6. Japan Society of Civil Engineers: Standard Specifications for Concrete Structures, Design, Maruzen(2007)(in Japanese)

7. Japan Society of Civil Engineers: Design Code for Steel Structures, Part B; Composite Structures, Maruzen(1997)(in Japanese) 